удк 340.131

\title{
C.A. Татаринов
}

\section{РОЛЬ КОНСТИТУЦИОННОГО СУДА РОССИЙСКОЙ ФЕДЕРАЦИИ В УКРЕПЛЕНИИ И РАЗВИТИИ КОНСТИТУЦИОННЫХ ЦЕННОСТЕЙ}

\begin{abstract}
Исследуется роль Конституционного Суда Российской Федерации по расширению воздействия фундаментальных конституционных ценностей на государственную деятельность. Отмечается влияние этих ценностей, содержащихся в его правовых позициях на правотворчество и правоприменение, направленное на обеспечение конституционности актов текущего законодательства, преодоление деформаций в правоприменении. Главной целью работы является выяснение познавательных и практических аспектов влияния деятельности Конституционного Суда на внедрение и распространение конституционных норм и ценностей, по углублению процессов конституционализации общественных отношений в нашей стране. Обосновывается специфика действия правовых позиций как нормативно-доктринальных правоустановлений, которые служат образцом поведения для государственных структур в конституционно-правовой практике, способны генерировать новые конституционные ценности.

Ключевые слова: Конституционный Суд Российской Федерации; конституционно-правовая доктрина; конституционноправовое мировоззрение и мышление; конституционные нормы и ценности; конституционализация текущего законодательства; решения и правовые позиции Конституционного Суда Российской Федерации.
\end{abstract}

Необходимость дальнейшего расширения процессов конституционно-правового регулирования общественных отношений в нашей стране предполагает повышение роли Конституционного Суда Российской Федерации по укреплению и развитию конституционных ценностей в ходе отправления конституционного правосудия, призванного способствовать осуществлению правотворческой, правоприменительной, нормативно-интерпретационной и теоретико-мировоззренческой основ становления и развития отечественного конституционализма. Выступая в качестве Основного Закона всего российского общества и государства, Конституция РФ является уникальным, базовым политико-правовым актом, содержащим в себе высшие юридические, социально-политические, духовно-нравственные начала, определяющие главные цели и задачи, пути и формы взаимодействия между личностью, гражданским обществом и государством. При этом речь прежде всего идет о признании, соблюдении и защите фундаментальных конституционных ценностей, пронизывающих всю архитектуру, смысл и содержание Конституции; об общеправовых конституционных ценностях, определяющих состав, структуру и статусные характеристики элементов организации и функционирования общества и государства (гл. 1, 2 и 9 Конституции РФ); специальных конституционных ценностях, раскрывающих особенности их действия в отдельных отраслях и сферах общественной и государственной жизни (гл. 3-8 Конституции РФ); ценностях, зафиксированных в Преамбуле Конституции, в значительной степени имеющих морально-нравственную, этическую нагрузку, отражающих цивилизованный подход развития человеческого сообщества и накопленный социально-культурный, национально-исторический опыт существования прошлых поколений народов России [1. С. 8; 2. С. 10]. К числу этих универсальных, общеправовых конституционных «мегаценностей» (целей, задач, принципов, идеалов) можно отнести такие, как суверенитет народа, демократия и народовластие, права и свободы человека и гражданина, уважение к праву и верховенство Конституции, составляющие систему общих конституционных ценностей, а также способствую- щие официальной легитимации и распространению общекультурных, гуманистических начал, которыми должны руководствоваться в своей правотворческой и правоприменительной деятельности уполномоченные субъекты конституционно-правовых отношений [3. C. 169-170].

Вместе с тем формальное учреждение и закрепление конституционных ценностей в Основном Законе совсем не означает их автоматического действия в реальной жизни и требует активного участия Конституционного Суда как главного хранителя Конституции РФ в обеспечении фактической возможности правильного правопонимания, реализации и защиты конституционных положений в конституционноправовой практике органов государственной и муниципальной власти, должностных лиц и публичных образований. В первую очередь таким основным направлением трансформации конституционных норм и ценностей в деятельность органов государственной власти в сфере правотворчества выступает выполнение Конституционным Судом РФ своей традиционной функции судебного конституционного контроля по проверке конституционности оспариваемых законодательных актов, предусматривающей в необходимых случаях признание их неконституционными, если они противоречат заложенным в Конституции важнейшим, базовым правоустановлениям. Как следствие, наиболее сложным вопросом в теории и практике осуществления нормоконтроля Конституционного Суда является измерение степени соответствия Конституции РФ актов текущего законодательства, исходя из существующей иерархии конституционных ценностей и особенностей их толкования, применения с учетом возникшей конкретной конституционно-правовой ситуации. В частности, наглядным примером может служить постановление Конституционного Суда РФ от 31 июля 1995 г., вынесенное по «чеченскому делу», когда он, анализируя соотношение разнопорядковых конституционных ценностей - прав и свобод личности и федерализма, - при разрешении сложившейся экстраординарной ситуации в субъекте РФ, отдал предпочтение принципу федерализма вопреки признанию приоритета в пользу принципа прав и свобод человека и гражданина как высшей ценности, который 
определяет смысл, содержание и принятие действий (актов) органов публичной власти (ст. 2, 18 Конституции РФ) [4]. Также в другом решении от 21 декабря 2005 г. по делу о назначении губернаторов Конституционный Суд, обосновывая порядок наделения глав исполнительной власти субъектов РФ полномочиями Президентом РФ, сославшись на происшедшие серьезные социальноправовые изменения в обществе, сделал спорный вывод о приоритете действия в этом случае принципа единства системы исполнительных органов государственной власти не равноценному по своему значению в системе конституционных ценностей принципу народовластия, предоставляющему возможность самостоятельно устанавливать в регионах процедуру прямых выборов губернаторов [5].

Не менее важное значение по оценке конституционности принятых законодательных актов Конституционным Судом РФ с точки зрения воплощения в них конституционных требований имеет не только соблюдение иерархии конституционных ценностей, но и правильное правопонимание природы и выстраивание отношений координации и гармонизации между ними в рамках измерения шкалы конституционных норм и ценностей [1. С. 12]. Именно таким господствующим типом правопонимания, лежащим в основе Конституции РФ, является естественно-правовая концепция объяснения природы прав и свобод индивида, ориентированная на конкретизацию и развитие конституционных положений в отраслевом законодательстве в контексте достижения главной цели - признания приоритета прав и свобод человека и гражданина и запрещение нарушения со стороны органов государственной власти базирующихся на них универсальных конституционных принципов - формального равенства, социальной справедливости и человеческого достоинства, обуславливающие особенности регулирования взаимодействия между личностью, гражданским обществом и государством [1. С. 5; 6. С. 9-10; 7. С. 457, 461, 471-472]. В результате разбирательства дел по защите нарушенных прав и свобод человека и гражданина Конституционным Судом были сформулированы определенные выводы, позволяющие наполнить фундаментальные конституционные ценности конкретным нормативным содержанием и следовательно оценивать конституционность принятых актов текущего законодательства:

1) поддержание доверия граждан к закону и действиям государства, предполагающего сохранение правовой определенности, разумной стабильности законодательной регламентации обязанностей лица перед государством, исключающее произвольное и несправедливое изменение исполнения действующих или установление новых юридических обязанностей;

2) недопустимость необоснованного и несправедливого отказа государства от исполнения своих социально-публичных функций перед населением либо неравного, дискриминационного подхода к предоставлению льгот и преимуществ нуждающимся категориям граждан, принадлежащих к одной социальной группе или находящихся в схожей обстановке;

3) разумная соразмерность и справедливость введения ограничений федеральным законом прав и сво- бод личности в соответствии с преследуемыми государством конституционно значимыми целями и необходимостью обеспечения защиты конституционных ценностей;

4) гарантирование государством реализации права каждого лица на равную судебную защиту человеческого достоинства, предусматривающее возможность свободного доступа к правосудию, проведения справедливого и компетентного судебного разбирательства, а также обжалования и пересмотра в судебных решений в различных видах судопроизводств для исправления судебных ошибок;

5) установление конституционно-правовой ответственности государства перед личностью, что возможно путем принятия специального федерального закона за неисполнение или ненадлежащее исполнение своих конституционных обязанностей и при условии полного и справедливого возмещения причиненного вреда индивиду [7. С. 453-454; 8. С. 208-209; 9. С. 131-132].

Одновременно правотворческая деятельность органов государственной власти по конкретизации и развитию конституционных ценностей в актах текущего законодательства требует разработанные специальные юридические механизмы, направленные на поиск паритета и преодоление конкуренции смежных конституционных интересов во взаимоотношениях личности, гражданского общества и государства с учетом внесенных предложений и рекомендаций Конституционного Суда РФ по регулированию отельных видов частноправовых и публично-правовых отношений. В частности, Конституционный Суд, опираясь на баланс публичных и частных конституционных интересов в постановлении от 16 мая 2000 г. по делу о банкротстве коммерческой организации, рекомендовал законодателю обосновать передачу части имущества предприятия из конкурсного производства в муниципальную собственность для государственных и муниципальных нужд, исходя из действия принципов соблюдения публичных интересов и неприкосновенности частной собственности при условии выплаты соразмерной и справедливой компенсации собственнику, а в постановлении от 14 июля 2005 г. об установлении сроков исковой давности по рассмотрению налоговых нарушений признал правомерность в определенной правовой ситуации восстановления сроков привлечения налогоплательщика к ответственности за совершение налогового правонарушения, руководствуясь целями формирования устойчивой бюджетной системы и сохранения свободы экономической деятельности [10, 11]. Однако в наибольшей мере правообразующая роль Конституционного Суда по внедрению универсальных конституционных принципов и ценностей в сферу правотворчества проявляется, если он не ограничивается лишь констатацией возникшего правового пробела и необходимости его устранения законодательным способом вследствие признания оспариваемого акта неконституционным, но и стремится на основе выработанной собственной правовой позиции по разрешению конкретного конституционно-правового вопроса обосновать параметры разработки будущего правового акта в целях обес- 
печения единства и согласованности между Конституцией РФ и текущим законодательством, учитывая новое законодательное регулирование в выявленном конституционно-правовом смысле оспариваемых положений акта отраслевого законодательства. В качестве примера можно привести постановление Конституционного Суда РФ от 22 марта 2007 г. о признании неконституционной ранее действовавшей нормы проверяемого акта, ограничивавшего максимальный размер выплаты пособия по беременности, родам, и внесение предложения законодателю о новом порядке регулирования социальных выплат по аналогии с правами, закрепленными в международном трудовом праве и налоговом законодательстве об исчислении величины пособия соразмерно предшествующего среднего заработка женщины и ставки взимания единого социального налога, позволяющего гарантировать соблюдение универсальных конституционных ценностей как равенство, справедливость и достоинство при осуществлении права работника на государственное социальное обеспечение [12].

Следующим основным направлением претворения Конституционным Судом фундаментальных конституционных ценностей в конституционно-правовую политику является конституционализация правоприменительной деятельности органов публичной власти, призванная провести своеобразную ее «очистку» от дефектов и коллизий, вызванных искажением смысла оспариваемой нормы акта текущего законодательства, придаваемой ей толкованием в конкретном деле или сложившейся правоприменительной практике судебными и иными правоприменительными органами. В этих случаях Конституционный Суд РФ обычно воздерживается объявлять такую норму правового акта не соответствующей Конституции для предотвращения возникновения пробела в законодательном регулировании и необходимости внесения корректив в отраслевое законодательство и предполагает скорректировать сферу ее действия в новой интерпретации, исключающей в дальнейшем неконституционное применение юридической нормы, расходящееся с выявленным конституционно-правовым смыслом даваемого в решении Конституционного Суда. Таким наглядным примером может служить постановление Конституционного Суда РФ от 3 февраля 2010 г., в котором он расширительно истолковал условия выплаты ежемесячной денежной компенсации военнослужащим, проходящим военную службу по контракту, найма (поднаема) жилых помещений, включенных в списки на улучшение жилищных условий и уволенных либо подлежащих увольнению со службы до 1 января 2005 г., ибо иное понимание и применение оспариваемой нормы законодательного акта нарушает принципы равенства и справедливости регулирования статуса личности и может привести на практике к произвольному ограничению реализации права в жилищных правоотношениях в отношении категории граждан, принадлежащих к одной и той же профессиональной группе лиц [13].

В другой схожей ситуации для преодоления имеющихся препятствий в правоприменительной деятельности органов публичной власти, связанных с отсутствием надлежащей нормативной базы в текущем законодательстве, Конституционный Суд может, опираясь на содержание универсальных конституционных принципов и ценностей, временно восстановить прежнее законодательное регулирование общественных отношений, затрагивающих права и свободы человека и гражданина, либо указать на обязанность прямого непосредственного применения Конституции РФ. Так, например в определении от 3 октября 2006 г. Конституционный Суд РФ признал возможным восстановить ранее установленный порядок приобретения права на получение льготной пенсии лицами, проработавшими в особо сложных и тяжелых условиях труда, предусмотренный прежним пенсионным законодательством, где измерения периодов времени на таких работах засчитываются в специальный трудовой стаж независимо от сроков его исчисления до или после 1 января 2003 г., исходя из действия принципов равенства и справедливости до момента принятия специального федерального закона о профессиональных пенсиях [14].

Если Конституционный Суд приходит к выводу, что объявление правового акта неконституционным предполагает возникновение пробела в законодательном регулировании, который нельзя будет восполнить прямым применением Конституции РФ либо конституционно-правовым истолкованием оспариваемых положений проверяемого нормативного акта, и существует необходимость внесения существенных изменений в текущее законодательство, то он вправе признать оспариваемые нормы в определенной части не противоречащими Конституции для предупреждения наступления негативных юридических последствий, вызванных повторным нарушением в правоприменительной практике основных прав и свобод личности. В частности, Конституционный Суд РФ в постановлении от 5 февраля 2007 г. признал соответствующими Конституции ряд оспариваемых положений ГПК РФ в части, касающейся совершенствования законодательной регламентации способов пересмотра и отмены вынесенных судебных решений в надзорном порядке, обеспечивающих соблюдение конституционных норм и принципов, таких как равенство, справедливость и достоинство, по восстановлению и охране нарушенного конституционного права индивида на судебную защиту путем применения надлежащих юридических процедур выявления, проверки и исправления судебных ошибок в надзорной инстанции [15].

Еще одним важнейшим правовым механизмом, способствующим утверждению и реализации фундаментальных конституционных ценностей в отечественной конституционно-правовой практике, является нормативно-интерпретационная функция Конституционного Суда, направленная на уяснение и разъяснение смысла и содержания Конституции РФ и отраслевого законодательства, обуславливающая выяснение эксплицитных и имплицитных связей и отношений, складывающихся между конституционными положениями и актами текущего законодательства, получающими свое отражение в сфере правотворчества, правоприменения и толкования в деятельности органов публичной власти [16. С. 15, 17, 20; 17. С. 60]. 
В результате адекватного конституционно-правового истолкования буквы и духа Конституции и текущего законодательства Конституционный Суд РФ обеспечивает гармоничное единство и взаимодействие универсальных конституционных принципов и ценностей высшего юридического уровня с предметом регулирования отраслевых законодательных актов, устанавливает и поддерживает разумный конституционный баланс между различными отраслями и институтами в рамках системы российского права, способствует их взаимному обогащению и выработке на базе создаваемого конституционно-правового фундамента особого вида нормативно-доктринальных правоустановлений как своих правовых позиций, сочетающих в себе признаки присущие предписаниям нормативных правовых актов, и выводы, свойственные конституционно-правовой доктрине [18. С. 81-82; 7. С. 12, 128-129, 142]. Выступая в качестве своеобразной квинтэссенции содержания принятого решения, правовые позиции Конституционного Суда представляют собой совокупность нормативно-интерпретационных установок, аргументов и оценок осмысления конституционных дефиниций и принципов, раскрывающих необходимость трансформации конституционных ценностей в текущее законодательство и в правоприменительную практику в случаях повторения схожих (аналогичных) конституционно-правовых ситуаций по разрешению конкретных конституционно-правовых вопросов и в целом влияющих на процессы развития российского конституционализма. Но особенно «квазиправотворческая» роль Конституционного Суда РФ как главного интерпретатора Конституции РФ возрастает тогда, когда он посредством конституционноправового истолкования смысла и содержания Конституции и массива отраслевого законодательства для преодоления неопределенности понимания конституционных положений в ходе осуществления судебного конституционного контроля может генерировать новые конституционные ценности:

1) уточняет содержание нормативного материала статьи закона;

2) устраняет коллизию, конфликтность между несколькими нормами права в поисках баланса содержащихся в них конкурирующих конституционных ценностей;

3) выясняет системные, иерархические связи и корреляции между отдельными нормами правовых институтов конкретной отрасли российского права;

4) раскрывает нормативное содержание частей статьи закона, если имеются определенные коллизии и пробельность внутренней структуры элементов юридической нормы акта;

5) обеспечивает рихтовку закона до конституционного уровня и придает ему новое нормативное содержание, соответствующее реалиям правового регулирования общественных отношений, и тем самым за счет уплотнения новым конституционно-правовым материалом удается избежать необходимость внесения серьезных изменений и дополнений в проверяемые законодательные акты [7. С. 131, 271, 292].

В частности, неоднократно в своих правовых позициях Конституционный Суд фактически легализо- вал многие новые конституционные ценности, которые вербально прямо не закреплены в тексте Основного Закона и вытекают из толкования духа интерпретированных положений Конституции РФ, таких как правовая безопасность и определенность, стабильность и предсказуемость регулирования публичных правоотношений, устойчивость условий хозяйствования, поддержание баланса публичных и частных интересов государства и предпринимательских структур, оказывающих существенное конституционно-правовое воздействие на функционирование системы национального права, правоприменительной практики и отвечающих перспективам развития российского общества и государства [7. С. 167-168].

Непосредственно из необходимости обеспечения многоуровневого влияния конституционных ценностей и норм на государственную и общественную жизнь вытекает теоретико-мировоззренческая функция Конституционного Суда РФ, предусматривающая его активное участие в становлении и развитии конституционной идеологии, правосознания и культуры, в соответствии с которыми должно происходить установление теоретико-познавательной и доктринальноконцептуальной основ осуществления отечественного конституционализма. Как результат использования ценностно-ориентированного подхода по формированию конституционной идеологии деятельность Конституционного Суда посредством критического осмысления конституционных положений и реальной конституционно-правовой действительности служит надлежащей теоретико-практической базой, позволяющей в будущем генерировать в конституционноправовой науке новые идеи, представления, концепции, направленные на поиск баланса и консенсуса между естественными правами и свободами личности, суверенитетом государственной власти и позитивным правом в рамках взаимодействия личности, гражданского общества и государства, предполагающей реальное утверждение Конституции как Основного Закона, воплощающего в себе высшие нравственные, правовые и социально-культурные стандарты, идеалы, ориентиры, определяющие основные пути общественного и государственного развития нашей страны [7. С. 73-74, 98].

Не меньшее мировоззренческое значение для развития науки конституционного права имеет экспертно-аналитическая деятельность Конституционного Суда РФ, способствующая пополнению ее понятийного аппарата актуальной юридической информацией о назначении и содержании конституционных норм и ценностей, методологии разрешения возникающих различных конституционно-правовых проблем, а также выяснению общих закономерностей и тенденций осуществления современного состояния российского конституционализма [7. С. 124-125].

Наконец, особое культурно-воспитательное воздействие призваны оказывать решения и правовые позиции Конституционного Суда на внедрение и распространение важнейших конституционных ценностей в профессиональное правосознание, содействующие выработке конституционно-правового мышления по восприятию определенных установок, представлений, оценок в отечественной конституционно- 
правовой практике, побуждающие активизировать меры по формированию высокого уровня конститу- ционной культуры и воспитания среди органов публичной власти и их руководителей.

\section{ЛИТЕРАТУРА}

1. Маврин С.П. Конституционные ценности и их роль в российской правовой системе // Журнал конституционного правосудия. 2012. № 3 (27). C. 1-13.

2. Кондрашев А.А. Конституционные ценности в современном российском государстве: о конфликтах и девальвациях // Конституционное и муниципальное право. 2017. № 1. С. 6-13.

3. Витрук Н.В. Конституция Российской Федерации как ценность и конституционные ценности: вопросы теории и практики // Право, демократия и личность в конституционном измерении: (история, доктрина и практика). Избранные труды (1991-2012 гг.). М. : Норма, 2012. C. $165-175$.

4. Постановление Конституционного Суда Российской Федерации от 31 июля 1995 года № 10-П по делу о проверке конституционности Указа Президента Российской Федерации от 30 ноября 1994 г. № 2137 «О мероприятиях по восстановлению конституционной законности и правопорядка на территории Чеченской Республики», указа Президента Российской Федерации от 9 декабря 1994 г. № 2166 «О мерах по пресечению деятельности незаконных вооруженных формирований на территории Чеченской Республики и в зоне осетино-ингушского конфликта», постановления Правительства Российской Федерации от 9 декабря 1994 г. № 1360 «Об обеспечении государственной безопасности и территориальной целостности Российской Федерации, законности, прав и свобод граждан, разоружения незаконных вооруженных формирований на территории Чеченской Республики и прилегающих к ней регионов Северного Кавказа», указа Президента Российской Федерации от 2 ноября 1993 г. № 1833 «Об основных положениях военной доктрины Российской Федерации» // Российская газета. 1995. 11 августа.

5. Постановление Конституционного Суда Российской Федерации от 21 декабря 2005 года № 13-П по делу о проверке конституционности отдельных положений Федерального закона «Об общих принципах организации законодательных (представительных) и исполнительных органов государственной власти субъектов Российской Федерации» в связи с жалобами ряда граждан // Собрание законодательства Российской Федерации. 2006. № 3. Ст. 336.

6. Бондарь Н.С. Конституционные ценности - категория действующего права (в контексте практики Конституционного Суда России) // Журнал конституционного правосудия. 2009. № 6 (12). С. 1-11.

7. Бондарь Н.С. Судебный конституционализм в России в свете конституционного правосудия. М. : Норма; Инфра-М, 2011. 544 с.

8. Витрук Н.В. Верность Конституции. М. : РАП, 2008. 272 с.

9. Зорькин В.Д. Конституционно-правовое развитие России. М. : Норма: Инфра-М, 2011.720 с.

10. Постановление Конституционного Суда Российской Федерации от 16 мая 2000 года № 8-П по делу о проверке конституционности отдельных положений пункта 4 статьи 104 Федерального закона «О несостоятельности (банкротстве)» в связи с жалобой компании «Timber Holdings International Limited» // Собрание законодательства Российской Федерации. 2000. № 21. Ст. 2258.

11. Постановление Конституционного Суда Российской Федерации от 14 июля 2005 года № 9-П по делу о проверке конституционности положений статьи 113 Налогового кодекса Российской Федерации в связи с жалобой гражданки Г.А. Поляковой и запросом Федерального арбитражного суда Московского округа // Собрание законодательства Российской Федерации. 2005 . № 30 (ч. II). Ст. 3200.

12. Постановление Конституционного Суда Российской Федерации от 22 марта 2007 года № 4-П по делу о проверке конституционности положения части первой статьи 15 Федерального закона «О бюджете Фонда социального страхования Российской Федерации на 2002 год» в связи с жалобой гражданки Т.А. Баныкиной // Собрание законодательства Российской Федерации. 2007. № 14. Ст. 1742.

13. Постановление Конституционного Суда Российской Федерации от 3 февраля 2010 года № 3-П по делу о проверке конституционности абзаца второго пункта 14 статьи 15 Федерального закона «О статусе военнослужащих», пункта 4 Постановления Правительства Российской Федерации «О порядке выплаты денежной компенсации за наем (поднаем) жилых помещений военнослужащим - гражданам Российской Федерации, проходящим военную службу по контракту, гражданам Российской Федерации, уволенным с военной службы, и членам их семей» и пункта 1 Положения о выплате денежной компенсации за наем (поднаем) жилых помещений гражданам Российской Федерации, уволенным с военной службы, и членам их семей в связи с жалобой гражданина С.В. Глушкова // Российская газета. 2010. 12 февраля.

14. Определение Конституционного Суда Российской Федерации от 03 октября 2006 года № 471-О по запросу Курчатовского городского суда Курской области о проверке конституционности пункта 3 статьи 27 Федерального закона «О трудовых пенсиях в Российской Федерации» и по жалобе гражданки Степановой Ольги Александровны на нарушение ее конституционных прав той же нормой // Собрание законодательства Российской Федерации. 2007. № 5. Ст. 679.

15. Постановление Конституционного Суда Российской Федерации от 5 февраля 2007 года № 2-П по делу о проверке конституционности положений статей $16,20,112,336,376,377,380,381,382,383,387,388$ и 389 Гражданского процессуального кодекса Российской Федерации в связи с запросом Кабинета Министров Республики Татарстан, жалобами открытых акционерных обществ «Нижнекамскнефтехим» и «Хакасэнерго», а также жалобами ряда граждан // Собрание законодательства Российской Федерации. 2007. № 7. Ст. 932.

16. Бондарь Н.С. Аксиология судебного конституционализма: конституционные ценности в теории и практике конституционного правосудия. М. : Юрист, 2013. Вып. 2. 176 с.

17. Бондарь Н., Джагарян А. Прямое действие Конституции : генерация и гарантирование конституционным правосудием // Сравнительное конституционное обозрение. 2016. № 3 (112). С. 52-78.

18. Бондарь Н.С. Нормативно-доктринальная природа решений Конституционного Суда РФ как источников права // Журнал российского права. 2007. № 4. С. 75-85.

Статья представлена научной редакцией «Право» 21 марта 2018 г.

\section{THE ROLE OF THE CONSTITUTIONAL COURT OF THE RUSSIAN FEDERATION IN REINFORCEMENT AND DEVELOPMENT OF CONSTITUTIONAL VALUES}

Vestnik Tomskogo gosudarstvennogo universiteta - Tomsk State University Journal, 2018, 432, 224-230.

DOI: $10.17223 / 15617793 / 432 / 30$

Sergey A. Tatarinov, Tomsk State University (Tomsk, Russian Federation). E-mail: cafedra206@mail.ru

Keywords: Constitutional Court of the Russian Federation; constitutional doctrine; constitutional ideology and reasoning; constitutional norms and values; constitutionality of existing legislation; decisions and legal positions of the Constitutional Court of the Russian Federation.

The aim of this article is to study the theoretical and practical questions of influence of the Constitutional Court of the Russian Federation on the formation and development of constitutional values according to which the constitutionality of different spheres and parts of public and state life should be carried out. On the basis of specific scientific methods (systematic, formal- legal, method 
of legal hermeneutics) and analysis of the decisions of the Constitutional Court of the Russian Federation, in the framework of the proposed classification of constitutional norms and values, the author pays special attention to the functioning of the principles of equality, social justice, human dignity that penetrate the most important aspects of relations between the person, society and the state. Primarily, the Constitutional Court of the Russian Federation influences the implementation of constitutional values in the legislation of state organs by providing stability of regulation of a person's duties before the state and by prohibiting groundless and unfair refusal of the state to fulfill public and social obligations before people, by making inequality in exemption and advantages to citizens of one social group inadmissible, by introducing rational, proportional and fair restrictions of the main rights and freedoms, by guaranteeing the realization of possibility to equal and fair judicial defense, by making the state legally liable before the person under conditions of complete and just compensation of harm. Besides, the constitutional influence of the Constitutional Court on legislation supposes the determination of hierarchy and balance inside the system of competitive constitutional values, maintaining of balance of personal legal and public legal interests, overruling of legal deformations and grounding of elaboration and admission of characteristics of future legislative acts that involve the rights and freedoms of a person. Therefore, expansion of the influence of constitutional values by the Constitutional Court of the Russian Federation on law enforcement by organs of public authority corrects the action sphere of debatable norms in a new interpretation, which in future excludes its implementation, which is different from the constitutional sense; it restores a previous legislative regulation or it admits the possibility of action of this norm as recognized and which non-contradicting to constitutional statements in a particular part. The interpretational function of the Constitutional Court on interpretation of the Constitution of the Russian Federation and sectoral legislation has a big practical value for establishing fundamental constitutional values in the activity of public organs, for it presupposes creation of legal statements as particular regulatory and doctrinal determinations, which are examples of behavior in constitutional practice and are able to generate new constitutional values.

\section{REFERENCES}

1. Mavrin, S.P. (2012) Konstitutsionnye tsennosti i ikh rol' v rossiyskoy pravovoy sisteme [Constitutional values and their role in the Russian legal system]. Zhurnal konstitutsionnogo pravosudiya. 3 (27). pp. 1-13.

2. Kondrashev, A.A. (2017) Constitutional values in the modern Russian state: conflicts and devaluations. Konstitutsionnoe i munitsipal'noe pravo. 1. pp. 6-13. (In Russian).

3. Vitruk, N.V. (2012) Pravo, demokratiya i lichnost'v konstitutsionnom izmerenii: (istoriya, doktrina i praktika). Izbrannye trudy (1991-2012 gg.) [Law, Democracy and Personality in the Constitutional Dimension: (History, Doctrine and Practice). Selected works (1991-2012)]. Moscow: Norma. pp. $165-175$.

4. Rossiyskaya gazeta. (1995) Ruling of the Constitutional Court of the Russian Federation of July 31, 1995, No. 10-P on the case on verification of the constitutionality of the Decree of the President of the Russian Federation of 30 November 1994 No. 2137 "On measures to restore constitutional legality and law and order on the territory of the Chechen Republic, of the Russian Federation of 9 December 1994 No. 2166 "On measures to curb the activities of illegal armed groups on the territory of the Chechen Republic and in the zone of the Ossetian-Ingush conflict", the Government of Russia of 9 December 1994 No. 1360 "On ensuring state security and the territorial integrity of the Russian Federation, legality, citizens' rights and freedoms, disarming of illegal armed formations on the territory of the Chechen Republic and the adjacent regions of the North Caucasus", the decree of the President of the Russian Federation of 2 November 1993 No. 1833 "On the main provisions of the military doctrine of the Russian Federation". Rossiyskaya gazeta. 11 August. (In Russian).

5. Russian Federation. (2006) Postanovlenie Konstitutsionnogo Suda Rossiyskoy Federatsii ot 21 dekabrya 2005 goda № 13-P po delu o proverke konstitutsionnosti otdel'nykh polozheniy Federal'nogo zakona "Ob obshchikh printsipakh organizatsii zakonodatel'nykh (predstavitel'nykh) i ispolnitel'nykh organov gosudarstvennoy vlasti sub"ektov Rossiyskoy Federatsii" v svyazi s zhalobami ryada grazhdan [Decision of the Constitutional Court of the Russian Federation of 21 December 2005 No. 13-P on the case on verification of the constitutionality of certain provisions of the Federal Law "On general principles of the organization of legislative (representative) and executive bodies of state power of the constituent entities of the Russian Federation" in connection with the complaints of a number of citizens]. Sobranie zakonodatel'stva Rossiyskoy Federatsii. 3. Art. 336 .

6. Bondar', N.S. (2009) Konstitutsionnye tsennosti - kategoriya deystvuyushchego prava (v kontekste praktiki Konstitutsionnogo Suda Rossii) [Constitutional values - the category of the current law (in the context of the practice of the Constitutional Court of Russia)]. Zhurnal konstitutsionnogo pravosudiya. 6 (12). pp. 1-11.

7. Bondar', N.S. (2011) Sudebnyy konstitutsionalizm v Rossii v svete konstitutsionnogo pravosudiya [Judicial constitutionalism in Russia in the light of constitutional justice]. Moscow: Norma; Infra-M.

8. Vitruk, N.V. (2008) Vernost' Konstitutsii [Fidelity to the Constitution]. Moscow: RAP.

9. Zor'kin, V.D. (2011) Konstitutsionno-pravovoe razvitie Rossii [Constitutional and legal development of Russia]. Moscow: Norma: Infra-M.

10. Russian Federation. (2000) Postanovlenie Konstitutsionnogo Suda Rossiyskoy Federatsii ot 16 maya 2000 goda № 8-P po delu o proverke konstitutsionnosti otdel'nykh polozheniy punkta 4 stat'i 104 Federal'nogo zakona "O nesostoyatel'nosti (bankrotstve)" v svyazi s zhaloboy kompanii "Timber Holdings International Limited" [Ruling of the Constitutional Court of the Russian Federation No. 8-P of 16 May 2000 on the case of verification of the constitutionality of certain provisions of Paragraph 4 of Article 104 of the Federal Law "On Insolvency (Bankruptcy)" in connection with the complaint of Timber Holdings International Limited]. Sobranie zakonodatel'stva Rossiyskoy Federatsii. 21. Art. 2258.

11. Russian Federation. (2005) Postanovlenie Konstitutsionnogo Suda Rossiyskoy Federatsii ot 14 iyulya 2005 goda № 9-P po delu o proverke konstitutsionnosti polozheniy stat'i 113 Nalogovogo kodeksa Rossiyskoy Federatsii v svyazi s zhaloboy grazhdanki G.A. Polyakovoy i zaprosom Federal'nogo arbitrazhnogo suda Moskovskogo okruga [Ruling of the Constitutional Court of the Russian Federation of July 14 2005 No. 9-P on the case on verification of the constitutionality of the provisions of Article 113 of the Tax Code of the Russian Federation in connection with the complaint of citizen G.A. Polyakova and the request of the Federal Arbitration Court of the Moscow District]. Sobranie zakonodatel'stva Rossiyskoy Federatsii. 30(II). Art. 3200.

12. Russian Federation. (2007) Postanovlenie Konstitutsionnogo Suda Rossiyskoy Federatsii ot 22 marta 2007 goda № 4-P po delu o proverke konstitutsionnosti polozheniya chasti pervoy stat'i 15 Federal'nogo zakona “O byudzhete Fonda sotsial'nogo strakhovaniya Rossiyskoy Federatsii na 2002 god" v svyazi s zhaloboy grazhdanki T.A. Banykinoy [Ruling of the Constitutional Court of the Russian Federation of 22 March 2007 No. 4-P on the case on the verification of the constitutionality of the provision of Part One of Article 15 of the Federal Law "On the Budget of the Social Insurance Fund of the Russian Federation for 2002" in connection with the complaint of the citizen TA. Banykina]. Sobranie zakonodatel'stva Rossiyskoy Federatsii. 14. Art. 1742.

13. Rossiyskaya gazeta. (2010) Ruling of the Constitutional Court of the Russian Federation of 3 February 2010 No. 3-P on the case on the verification of the constitutionality of the second paragraph of Paragraph 14 of Article 15 of the Federal Law "On the Status of Servicemen", Paragraph 4 of the Decree of the Government of the Russian Federation "On the procedure for payment of cash compensation for renting (sublease) of accommodation to servicemen - citizens of the Russian Federation who are on military service under contract, to citizens of the Russian Federation dismissed from military service and members of their families" and Paragraph 1 of the Regulation on payment of money compensation for renting (sublease) of residential premises to citizens of the Russian Federation discharged from military service, and members of their families in connection with the complaint of citizen S.V. Glushkov. Rossiyskaya gazeta. 12 February. (In Russian). 
14. Russian Federation. (2007) Opredelenie Konstitutsionnogo Suda Rossiyskoy Federatsii ot 03 oktyabrya 2006 goda № 471-O po zaprosu Kurchatovskogo gorodskogo suda Kurskoy oblasti o proverke konstitutsionnosti punkta 3 stat'i 27 Federal'nogo zakona "O trudovykh pensiyakh v Rossiyskoy Federatsii” i po zhalobe grazhdanki Stepanovoy Ol'gi Aleksandrovny na narushenie ee konstitutsionnykh prav toy zhe normoy [Resolution of the Constitutional Court of the Russian Federation of 3 October 2006 No. 471-O at the request of the Kurchatov city court of Kursk oblast on the verification of the constitutionality of Paragraph 3 of Article 27 of the Federal Law "On Labor Pensions in the Russian Federation" and at the complaint of Olga Stepanova on the violation of her constitutional rights by the same norm]. Sobranie zakonodatel'stva Rossiyskoy Federatsii. 5. Art. 679.

15. Russian Federation. (2007) Postanovlenie Konstitutsionnogo Suda Rossiyskoy Federatsii ot 5 fevralya 2007 goda № 2-P po delu o proverke konstitutsionnosti polozheniy statey 16, 20, 112, 336, 376, 377, 380, 381, 382, 383, 387, 388 i 389 Grazhdanskogo protsessual'nogo kodeksa Rossiyskoy Federatsii v svyazi s zaprosom Kabineta Ministrov Respubliki Tatarstan, zhalobami otkrytykh aktsionernykh obshchestv "Nizhnekamskneftekhim" i "Khakasenergo", a takzhe zhalobami ryada grazhdan [Ruling of the Constitutional Court of the Russian Federation No. 2-P of 5 February 2007 on the case on the verification of the constitutionality of the provisions of Articles 16, 20, 112, 336, 376, 377, 380, 381, 382, 383, 387, 388 and 389 of the Civil Procedure Code of the Russian Federation in connection with the request of the Cabinet of Ministers of the Republic of Tatarstan, complaints of open joint-stock companies "Nizhnekamskneftekhim" and "Khakasenergo", as well as complaints of a number of citizens]. Sobranie zakonodatel'stva Rossiyskoy Federatsii. 7. Art. 932.

16. Bondar', N.S. (2013) Aksiologiya sudebnogo konstitutsionalizma: konstitutsionnye tsennosti v teorii i praktike konstitutsionnogo pravosudiya [Axiology of judicial constitutionalism: constitutional values in the theory and practice of constitutional justice]. Is. 2. Moscow: Yurist.

17. Bondar', N.S. \& Dzhagaryan, A. (2016) Pryamoe deystvie Konstitutsii: generatsiya i garantirovanie konstitutsionnym pravosudiem [Direct action of the Constitution: generating and guaranteeing constitutional justice]. Sravnitel'noe konstitutsionnoe obozrenie. 3 (112). pp. 52-78.

18. Bondar, N.S. (2007) Normativno-doktrinal'naya priroda resheniy Konstitutsionnogo Suda RF kak istochnikov prava [Normative-doctrinal nature of the decisions of the Constitutional Court of the Russian Federation as sources of law]. Zhurnal rossiyskogo prava. 4. pp. 75-85.

Received: 21 March 2018 